\title{
Marginal donors and organ shortness: Coronary artery revascularization during heart transplantation.
}

\author{
Antonio Piperata ${ }^{1}$, TOMASO BOTTIO ${ }^{2}$, Martina Avesani ${ }^{2}$, and Gino Gerosa ${ }^{1}$ \\ ${ }^{1}$ Affiliation not available \\ ${ }^{2}$ Universita degli Studi di Padova Dipartimento di Medicina
}

October 8, 2020

\begin{abstract}
ABSTRACT Heart transplantation is the gold standard treatment for patients with end-stage heart failure. The limited availability of organs has led to the expansion of the donor criteria by introducing the use of marginal donors. Although the use of marginal donors has reduced waiting lists, the results are worse than with standard donors. For this reason, the use of marginal donors in clinical practice is still controversial. We describe two cases of heart transplantation from marginal donors with pre-transplant angiography evidence of coronary stenosis and normal ventricular function.
\end{abstract}

\section{Hosted file}

JOCS.pdf available at https://authorea.com/users/323792/articles/485609-marginal-donors-andorgan-shortness-coronary-artery-revascularization-during-heart-transplantation

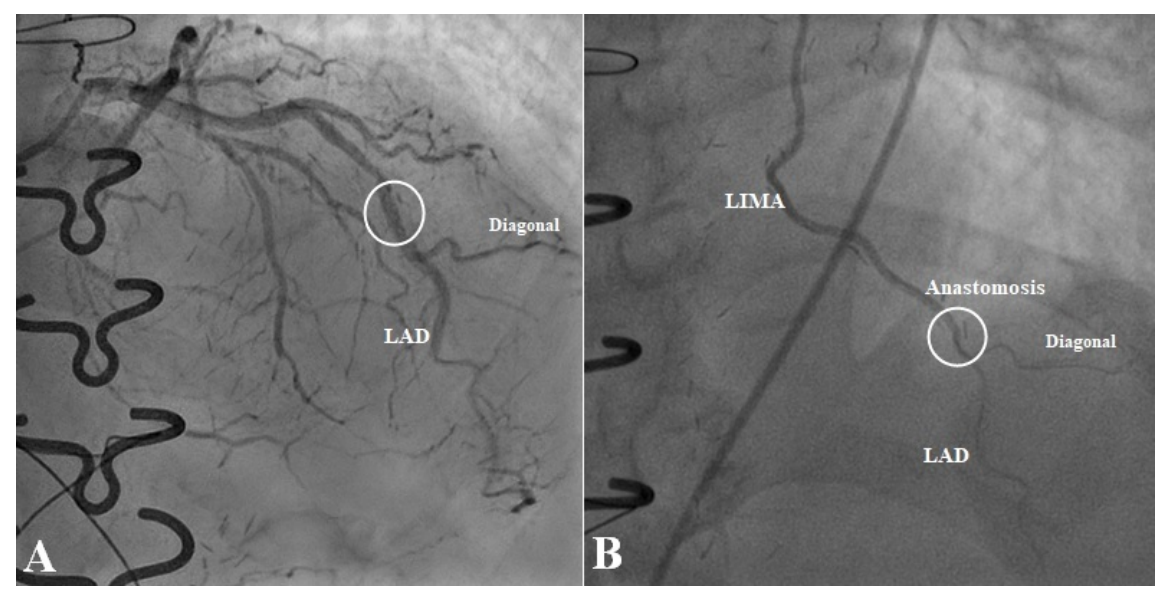



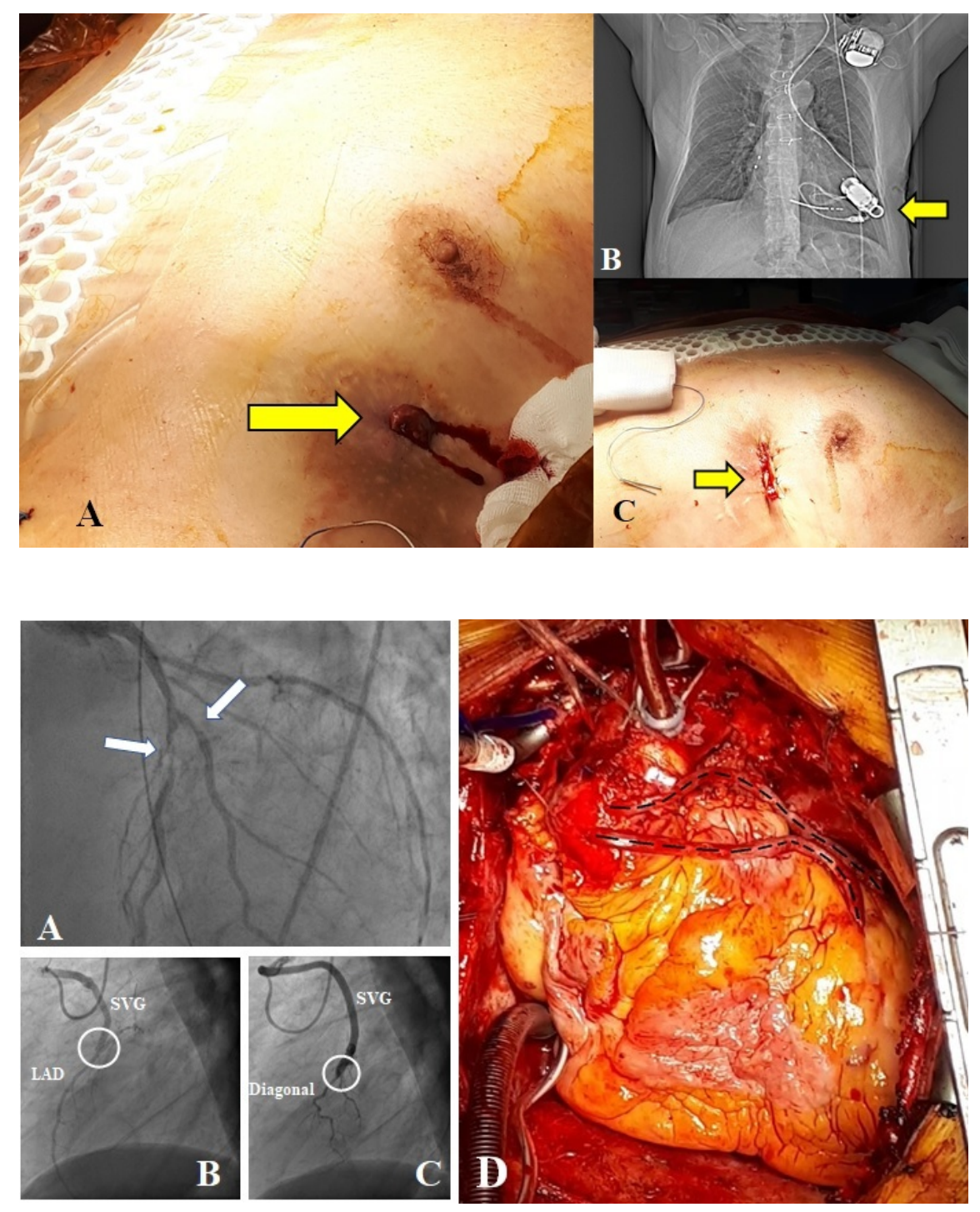